\title{
Selective Grafting of Polyamines to Polyether Ether Ketone Surface during Molding and Its Use for Chemical Plating
}

\author{
Jürgen Nagel *(1), Philipp Zimmermann, Simona Schwarz and Kornelia Schlenstedt \\ Leibniz-Institut für Polymerforschung Dresden e.V., Hohe Straße 6, 01069 Dresden, Germany; \\ zimmermann-philipp@ipfdd.de (P.Z.); simsch@ipfdd.de (S.S.); schlenstedt@ipfdd.de (K.S.) \\ * Correspondence: nagel@ipfdd.de; Tel.: +49-351-4658-399; Fax: +49-351-4658-290
}

Received: 29 August 2018; Accepted: 19 September 2018; Published: 22 September 2018

\begin{abstract}
We present a new approach of surface functionalization of polyether ether ketone (PEEK) that is carried out during the molding step. Thin films of polymers with different functional groups were applied to the surface of a mold and brought in close contact with a PEEK melt during injection molding. The surfaces of the produced parts were characterized after solidification. Only those PEEK surfaces that were in contact with polymers bearing primary amino groups exhibited a wettability for water. Obviously, the thin polymer film was grafted to the surface by a chemical reaction initiated by the high melt temperature. The formation of azomethine bonds between PEEK and the polyamine by coupling to the ketone groups was proposed. The other amino groups in the molecule were still in function after the molding process. They adsorbed different anionic molecules and anionic charged nanoparticles from aqueous solutions. The surfaces could be chemically plated by copper and nickel with high adhesion.
\end{abstract}

Keywords: polyether ether ketone (PEEK); adhesion; surface modification; injection molding; plating; hydrogel layers

\section{Introduction}

Polyether ether ketone (PEEK) is a high performance thermoplastic polymer that features a high modulus and mechanical strength even at high temperature and a high chemical stability. It is flame resistant, and combustion is self-quenching. Moreover, it is physiologically harmless. Therefore, it is used in medical devices and artificial replacements, e.g., for bone and dental implants. The chemical stability is used in devices for the chemical industry and food industry. Its high mechanical strength at relatively low density and its flame resistance are advantageous for aviation and for the construction of vehicles. Its stiffness is a result of the high content of aromatic hydrocarbon rings in the molecule. Unfortunately, this makes PEEK sensitive to ultra violet radiation. That is one reason why a coating of PEEK parts is often required. Design aspects are another reason. However, PEEK surfaces are rather non-polar, and a surface modification is required for high adhesion of coatings [1,2]. The polymerization of dopamine results in a modified surface, which is able to immobilize proteins, but the mechanical adhesion of the poly dopamine would not be sufficient for bonding a thick metal layer [3]. A direct grafting method was developed that takes advantage of the reactivity of the ketone group [4]. Here, polyvinyl alcohol was attached via the formation of acetals. Then, glycidyl groups were attached to the hydroxyl groups of polyvinyl alcohol, and finally a diamine was attached via the glycidyl groups. This method is rather expensive, and the modification effect is not stable over a long period of time. Treatment with different types of plasma is often used for modifying the surfaces of polymers. An efficient method with high industrial relevance is flame impingement. Treatment with 
defined plasmas, e.g., low pressure plasma, atmospheric plasma, or corona, in the presence of different gases gives a better control of chemical modification [5-17]. However, only the PEEK segments on the outermost surface layer are converted to functional groups like carboxyl, hydroxyl, carbonyl, and amide. Control of composition is difficult. Since PEEK absorbs ultraviolet irradiation, it was used for chemical surface modification and grafting [18-20]. Due to the high-energy treatments, a high diversity of different functional groups are formed on the surface, but the effect is usually not permanent [21,22]. The combination of plasma treatment and grafting a functional polymer layer from the PEEK surface results in reliable surface modification, but at high operating expense [23]. A high adhesion of a metal layer is supported by a micro structure on the surface. This can be realized by plasma etching, chemical etching, laser etching or mechanical etching, e.g., with sandblasting [24-26]. There are other processes in use, but all of them require an additional processing step. Any pre-treatment step requires production space, investment, and running costs, e.g., for materials, energy, and labor expense. Integrating the surface modification with the molding step would be very efficient. This was demonstrated, e.g., by structuring the part surface using a micro structured mold surface [27].

In our paper, we present an approach for the chemical surface modification that is carried out during injection molding of the part. It is based on the deposition of a thin film of a functional and reactive polymer, the so-called modifier, on the mold surface of an injection molding machine. The high temperature of the melt is used to initiate a coupling reaction. Treatment in the melt state features additional advantages over part treatments. e.g., a high mobility of chain segments and a higher excluded volume. Side reactions are minimized due to the rapid cooling and the small reaction time. The effect is much larger compared to the pre-treated surfaces due to grafting of a relatively thick functional polymer layer to the thermoplastic surface. The reaction proceeds in only one step and is integrated in the molding step of the part. The important issue is to identify a reactant and a suitable reaction pathway for the thermoplastic under consideration. Solutions for polycarbonate (PC), polypropylene (PP), grafted PP, polystyrene (PS), and polyamide (PA) have already been published [28-33]. The carbonate group in PC was reacted with polyethylene imine during molding under formation of a urethane bond, resulting in a relatively thick layer of a functional polymer on the PC surface. Parts rinsed in water did not dewet due to the high hydrophilicity. PP was modified by radical grafting of acrylic acid. The high reactivity of a cyclic carboxylic anhydride was used to graft a maleic anhydride-ethylene copolymer to PA 6. PS contains electron-rich phenyl rings. Here, we applied Friedel-Crafts acylation using mixed anhydrides to attach a polycarboxylic acid on the melt surface during 3D printing. In this paper, we tested different functional groups for chemical coupling onto PEEK surfaces. A reaction pathway is proposed. Finally, chemical plating was carried out, which demonstrates the effect of surface modification for industrial use. This application is of high impact, as a metal composite with PEEK would support its usage for lightweight construction parts in vehicles, aircraft and spacecraft. Moreover, this type of surface modification of PEEK may also be used for other applications.

\section{Experimental}

The different types of polymer modifiers (polyallyl amine (PAAm) $M_{\mathrm{W}} 65 \mathrm{~kg} \cdot \mathrm{mol}^{-1}$; hyper branched polyethylene imine (PEI) $M_{\mathrm{w}} 700 \mathrm{~kg} \cdot \mathrm{mol}^{-1}$; polyvinyl alcohol (PVA) $M_{\mathrm{w}} 23 \mathrm{~kg} \cdot \mathrm{mol}^{-1}$, degree of hydrolysis $89 \%$; polyacrylic acid (PAc) $M_{\mathrm{W}} 450 \mathrm{~kg} \cdot \mathrm{mol}^{-1}$ ) and $\mathrm{CuSO}_{4} \cdot 5 \mathrm{H}_{2} \mathrm{O}$ were supplied by Sigma-Aldrich (Schnelldorf, Germany). PEEK (Vestakeep 3300, Evonik Industries AG, Marl, Germany) was used as thermoplastic material. It was dried at $160^{\circ} \mathrm{C}$ for $4 \mathrm{~h}$ in vacuum. Melt and mold temperatures were 360 and $160^{\circ} \mathrm{C}$, respectively. Typical molding conditions as suggested by the manufacturer were used.

The general processing steps are explained in Figure 1. Fundamental molding investigations were carried out in the first stage with a small Boy injection molding machine (BOY $22 \mathrm{~A} \mathrm{HV}$, Dr. Boy GmbH \& Co. KG, Neustadt-Fernthal, Germany). The $L / D$ ratio of the screw, screw speed, and pressure were 20, $60 \mathrm{~min}^{-1}, 400 \mathrm{MPa}$, respectively. It was equipped with an in-house build mold having an inlay with 
a magnetic substrate holder in which mirror-polished steel substrates with a diameter of $50 \mathrm{~mm}$ were mounted before each injection cycle [34]. The substrates were covered with a layer of the appropriate modifier by spin-coating in advance. This approach had the advantage that the applied modifier layer on the substrate can be characterized. The layer thickness on the substrate was measured by ellipsometry using a Multiskop 8.8 ellipsometer (Optrel GbR, Sinzing, Germany). After injection of PEEK and solidification, the substrate was separated from the formed part. Both surfaces were characterized. Dynamic contact angles against water were measured using an OCA35 XL (DataPhysics Instruments $\mathrm{GmbH}$, Filderstadt, Germany). The zeta potential of the polymer surfaces was measured with an electro kinetic analyzer EKA (Anton Paar GmbH, Graz, Austria). Some samples were dipped into a $10^{-3} \mathrm{M}$ solution of eosin $\mathrm{Y}$ in water at $\mathrm{pH} 9$ for $10 \mathrm{~min}$ to test the dye adsorption.

Scanning electron microscopy with energy-dispersive $\mathrm{X}$-ray spectroscopy (SEM-EDX) investigations were made with an Ultra Plus Gemini microscope (Carl Zeiss SMT GmbH, Oberkochen, Germany) using an XFlash 5060 F EDX detector (Bruker Nano GmbH, Berlin, Germany). Prior to the characterization, the parts were rinsed in copper sulfate solution for marking the amino groups, exploiting the complex formation between amino groups and the copper ions. After rinsing in water to remove excess copper ions and drying, they were coated with a Pt layer of $3 \mathrm{~nm}$ thickness by sputtering using a Leica EM SCD 050 (Leica Microsysteme GmbH, Wetzlar, Germany).

Samples for plating experiments were prepared on the injection-molding machine Ergotech 100/420-310 (Sumitomo-Demag Plastics Machinery GmbH, Schwaig, Germany). The $L / D$ ratio of the screw, injection pressure, rate, holding pressure and time and cooling time were 20,600 $\mathrm{MPa}$, $35 \mathrm{~mm} \cdot \mathrm{s}^{-1}, 350 \mathrm{bar}, 1 \mathrm{~s}, 25 \mathrm{~s}$, respectively. The modifier films were directly spray-coated from aqueous solutions on one side of the mold using an air brush at each cycle. The amount of dry modifier on the mold surface was calculated by volume and concentration of used solution per injection. It was about $250 \mathrm{mg} \cdot \mathrm{m}^{2}$. The prepared plates used for metallization experiments were rinsed in water for $6 \mathrm{~h}$ under stirring to remove unbound modifier. The plates were shaken first in a colloidal solution of gold nanoparticles (AuNP) for $30 \mathrm{~min}$. The synthesis of the AuNP was made using a classical approach [34]. After rinsing with water and drying, the plates were dipped in a copper bath, consisting of a solution of $6.25 \mathrm{~g} \cdot \mathrm{L}^{-1} \mathrm{CuSO}_{4} \cdot 5 \mathrm{H}_{2} \mathrm{O}, 8 \mathrm{~g} \cdot \mathrm{L}^{-1}$ EDTA, and $0.11 \mathrm{~g} \cdot \mathrm{L}^{-1} \mathrm{NaBH}_{4}$ at room temperature. The $\mathrm{pH}$ of this solution was adjusted to 12 by adding $\mathrm{NaOH}$. Plating with nickel was realized using a commercial nickel bath (SurTec International GmbH, Bensheim, Germany)

The metal layer thickness was measured by X-ray fluorescence analysis (XFA) using a Fischerscope X-ray Xan 220 (Helmut Fischer GmbH + Co. KG, Sindelfingen, Germany). The metallized plates were cut with a cross-hatch (Erichsen Mehrschneidegerät 295/I with 6 blades, Erichsen GmbH \& Co. KG, Hemer, Germany). An adhesive tape was fixed on the metal layer and then pulled off at an angle of $90^{\circ}$.

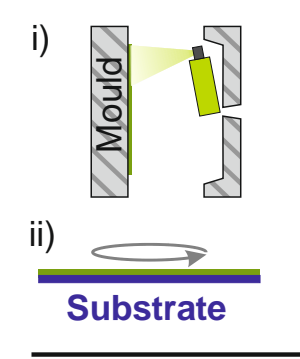

Step: 1.

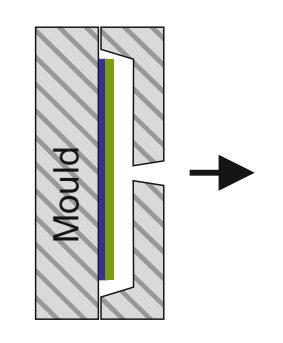

2.

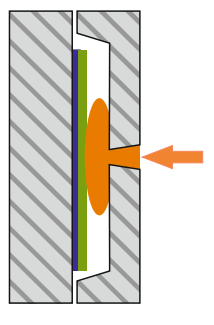

3.

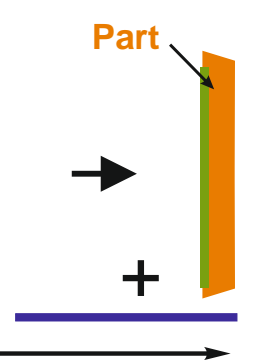

4.

Figure 1. Processing steps of surface modification during molding. 1. Formation of thin film $(10-100 \mathrm{~nm})$ of modifier by either (i) spray-coating or (ii) spin-coating; 2. Modifier layer on mounted substrate or directly on mold surface; 3 . Injection of the polyether ether ketone (PEEK) melt while initiating a coupling reaction, see also graphical abstract figure; 4 . Demolding with transfer of the modifier layer to the part. 


\section{Results and Discussion}

The thicknesses of the modifier layers on the substrates prior to molding are listed in Table 1. The modifier layer thickness was measured again after injection molding and removing of the PEEK part. The comparison with the thicknesses before molding revealed that they did not change significantly in the case of PAc. Obviously, no transfer of PAc from the substrate to the PEEK surface took place during molding. Thus, PAc did not interact with the PEEK melt. The same behavior was observed for the PVA layer. Obviously, no interaction between PEEK and PVA did occur either. On the other hand, the thickness of the PEI layer was reduced very much during molding. The PAAm layer was transferred almost completely. Obviously, only thin layers of polymers bearing primary amino groups were transferred to the PEEK surface during molding.

Table 1. Characteristics of the PEEK part surfaces.

\begin{tabular}{ccccc}
\hline \multirow{2}{*}{ Sample Type } & \multicolumn{2}{c}{ Layer Thickness/nm $^{\mathbf{a}}$} & \multicolumn{2}{c}{ Contact Angle/ $\mathbf{b}^{\mathbf{b}}$} \\
\cline { 2 - 5 } & After Preparation & After Molding & Advancing & Receding \\
\hline PEEK & - & - & 80 & 52 \\
PEEK-PAc & 36 & 34 & 83 & 52 \\
PEEK-PVA & 18 & 18 & 83 & 53 \\
PEEK-PEI & 115 & 14 & 68 & $<10$ \\
PEEK-PAAm & 79 & 2 & 84 & $<10$ \\
\hline
\end{tabular}

${ }^{\mathrm{a}}$ on substrate, after deposition; ${ }^{\mathrm{b}}$ of molded part, after extraction in ethanol, details in Table S1.

Eosin $Y$ was adsorbed only on surfaces modified with PAAm or PEI using the described process, but neither on samples without such modification nor on plain PEEK. This suggests the formation of a cationic surface on PEEK. Obviously, the polyamine-modified surface is charged positively by adsorption of protons from water and the formation of ammonium functions. Thus, the negatively charged dye adsorbed on this surface due to electrostatic interactions. The adsorbed dye could not be removed by rinsing with water, see also Figure S1.

The EDX spectrum of plain PEEK shows only signals for C, O in Figure 2. It did not show any copper signal. The spectra of parts modified with PEI exhibited intense peaks of $\mathrm{Cu}(\mathrm{L})$ as well as $\mathrm{S}(\mathrm{K})$ after dipping in copper sulfate solution, pointing to chemisorption of copper due to the formation of a very stable chelate complex with amino groups. This is an indication, that the amino groups were still functional and accessible, despite the thermal treatment during molding. The copper was evenly distributed on the PEEK surface, as shown in Figure S2.

The parts were then extracted in ethanol for $6 \mathrm{~h}$ in a Soxhlet apparatus. The extraction was intended to remove any unbound material. Ethanol is a good solvent for PAAm but do not swell or dissolve PEEK. Water was avoided as solvent because it could result in charging the PEEK surface, which would enhance the adsorption of PAAm due to electrostatic attraction, which was not intended. Moreover, water could result in hydrolyzation of some bonds. These samples were characterized by the following experiments.

The EDX spectrum of the sample modified with PEI after marking with copper exhibited a strong signal of copper that was only slightly smaller than that of the surface before extraction. Consequently, only a low amount of the polyamine was removed. This pointed to a covalent coupling of the polyamine layer according to Figure 3.

The dynamic contact angles were measured. The advancing angles of the differently prepared samples in Table 1 equalled almost those of the plain PEEK. The same relation was observed for the receding angles of samples treated with PAc and PVA. Thus, these polymers did not modify the PEEK surface during the proposed approach. However, the samples modified with PAAm or PEI exhibited receding angles lower than $10^{\circ}$ and in a range that could not be reliably measured. In addition, parts dipped into water did not dewet after drawing off the water. Swelling of a hydrophilic polymer layer may be an explanation for the high hysteresis [35]. A similar behavior was already studied at the 
surface modification of PC with polyamines during molding [29]. There, the amino groups were coupled onto the PC backbone by formation of an urethane bond.

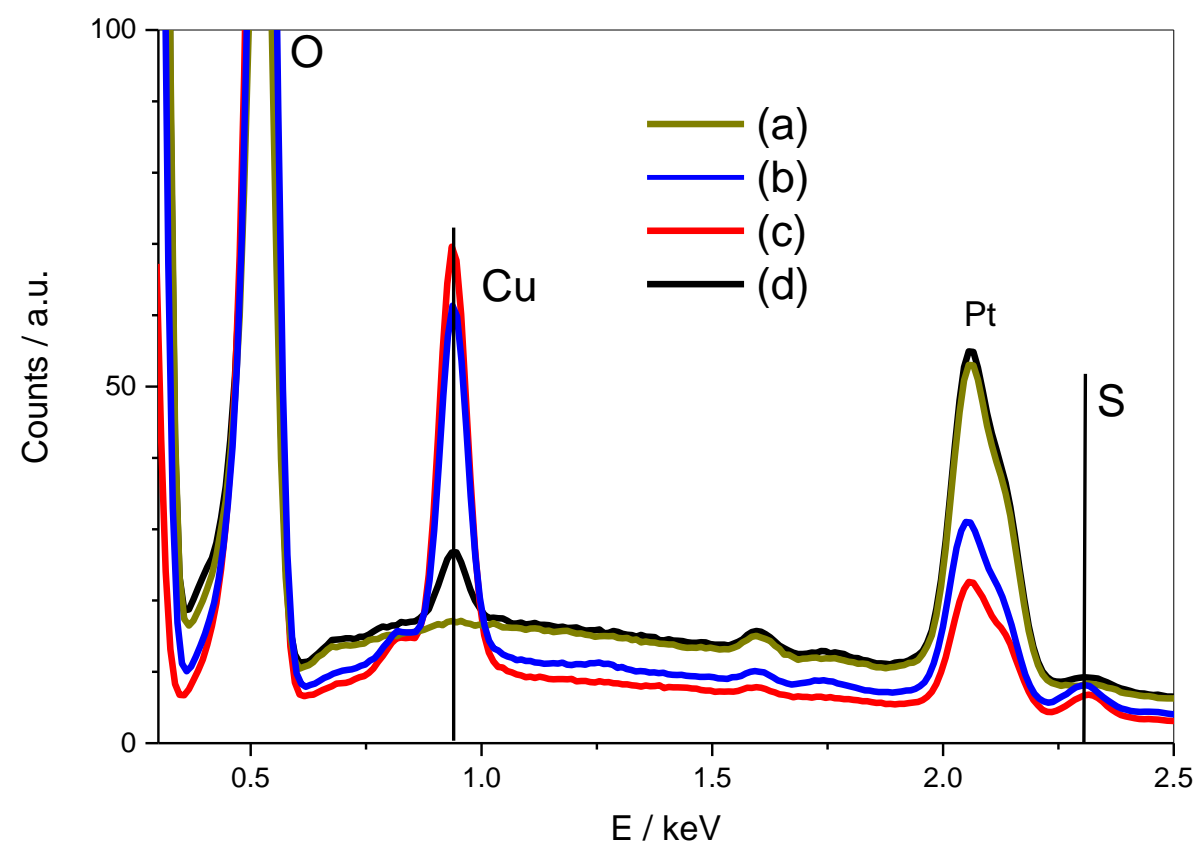

Figure 2. Energy-dispersive X-ray (EDX) spectra of PEEK samples, treated with $\mathrm{CuSO}_{4}$ solution. (a) Plain PEEK; (b) PEEK surface modified with polyethylene imine (PEI) during molding; (c) after extraction in ethanol; (d) after extraction in water at $\mathrm{pH}$ 3. The signals are marked with assigned elements. The Pt signals stem from the preparation procedure.<smiles>[R2]Oc1ccc(Oc2ccc(C(=O)c3ccc(O[R])cc3)cc2)cc1</smiles>

Figure 3. Schema of chemical coupling of a primary amino compound (the modifier M) to PEEK.

Some of the parts modified with PAAm or PEI and extracted in ethanol were additionally extracted for four hours in a Soxhlet apparatus in aqueous hydrochloride acid solution of $\mathrm{pH}$. The surfaces of these parts did not show any of the properties and behavior of that of those surfaces without this treatment. No staining, no wetting by water, almost no shift of the isoelectric point (see Figure S3) and no adsorption of copper did occur, as the EDX spectrum in Figure 2 revealed. Obviously, the polyamines were completely removed by acid-catalyzed hydrolysis in the aqueous environment, as suggested in Figure 3. Such a reaction is typical for azomethine bonds. Thus, the assumption of chemical grafting of the polyamines during molding by the primary amino groups according to Figure 3 is supported by this experiment.

Since the PAAm and PEI layers could not be removed by extraction in ethanol, chemical coupling of primary amino groups to ketone groups of the PEEK surface by formation of azomethine bonds was assumed. This assumption is supported by the fact that compounds with other functional groups (hydroxyl, carboxylic acid) were not transferred. The reactions between PEEK and primary amino compounds in solution at high temperature were studied extensively under different conditions in the literature [36-39]. Alternatively, the surfaces of PEEK plates were reacted in solutions of different components at elevated temperature $[40,41]$. Reasonable conversion was achieved there after many hours' reaction time. 
In contrast to the proposed reactions, our experiments were carried out under different conditions. The reaction temperature on melt-mold contact was high, i.e., about $300^{\circ} \mathrm{C}$. However, the reaction time during injection molding was much smaller due to the rapid cooling than in the solution experiments, and the concentration of reactive groups (ketone and amino) was much higher. Thermal simulations revealed a reaction time at high temperature of about $1 \mu$ s [42]. Hence, a reaction takes place only in a very small layer along the melt-modifier interface with a thickness of about $1 \mathrm{~nm}$ [43]. Interdiffusion is limited also by the immiscibility of the two materials. Thus, only molecular groups that come into close contact immediately after the melt hits the modifier layer on the mold can take part in a reaction. Therefore, the concentrations of those reactive groups in the interphase have to be high. In the case of PEEK, PEI and PAAm the concentrations of ketone groups and primary amino groups, respectively, are very high because not only the end groups but every repeating unit carries a reactive group. The reactivity of the components, the high concentrations, and the high temperature on the one hand and the transferred layer and its stability against solvent extraction on the other hand pointed to a reactive coupling of the modifiers over the primary amino groups. However, a direct proof of the reaction product will not be possible due to the low amount of products formed in the small interface layer. Moreover, even the plain PEEK is poorly soluble in almost all solvents, preventing the use of standard analytical tools like nuclear magnetic resonance spectroscopy. It is somewhat soluble in special solvents only at very high temperature (about $300^{\circ} \mathrm{C}$ ). The reaction products in the surface layer are even less soluble due to the formation of cross-links between many ketone groups of PEEK and many amino groups of the polyamine. Nevertheless, the solubility and chemical behavior point to the formation of a chemical bond according to Figure 3 as suggested by the reaction mechanism taken from literature.

Further investigations were carried out with parts with larger surface areas. The plates were cut in small pieces and extracted in ethanol in a Soxhlet apparatus for $6 \mathrm{~h}$ to remove unbound modifier. The zeta potential of the resulting plain PEEK surface was positive at low $\mathrm{pH}$ values and decreased with the $\mathrm{pH}$ value as shown in Figure 4 . The isoelectric point was at $\mathrm{pH}=4$. The zeta potential was constant at high $\mathrm{pH}$ with values of less than $-32 \mathrm{mV}$, which is typical for a non-polar polymer surface. The curve of the PEEK surface modified with PAAm was shifted to higher values. The isoelectric point was at about $\mathrm{pH}=5$. This suggests a more cationic surface than that of plain PEEK. The zeta potential then decreased continuously with $\mathrm{pH}$. In contrast to the plain PEEK surface, no constant value was approached in the measurement range. This pointed to functional groups, e.g., amino groups, within a finite polymer layer bound on the surfaces. The isoelectric point shifted even more to about 8 for the PEEK surface modified with PEI. The maximum potential in the acid range was about $40 \mathrm{mV}$, which was higher than in the case of PAAm. This revealed a complete change of the electro kinetic behavior compared to unmodified PEEK.

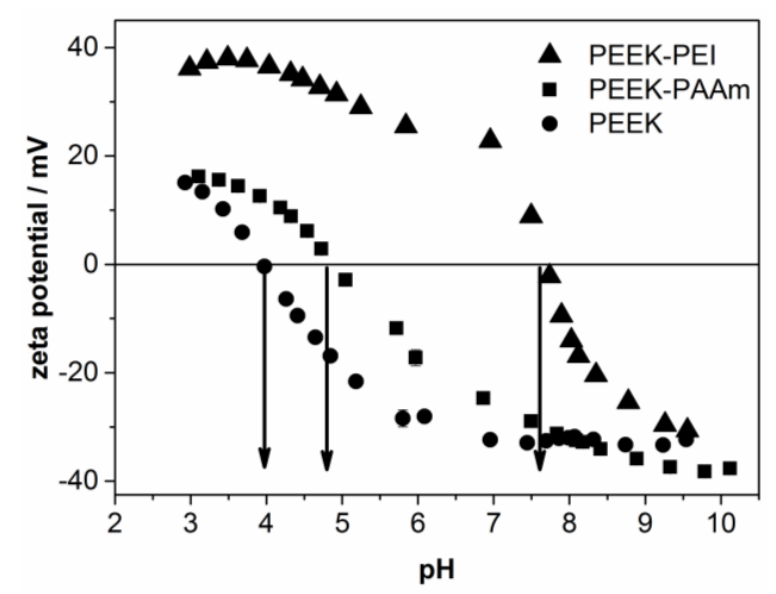

Figure 4. Zeta potentials of PEEK plates and plates chemically modified during molding with PEI or PAAm, respectively. After extraction in ethanol. The arrows point to the isoelectric points. 
The plates modified with PAAm or PEI, respectively, were rinsed in a solution of gold nanoparticles (AuNP, size about $20 \mathrm{~nm}$ ), which were prepared according to the description in a previous paper [34]. The red color of the surfaces revealed adsorption of AuNP only at the modified surface regions, i.e., where a polyamine layer was bound, see also Figure S4. These parts were then rinsed in the copper bath. After $60 \mathrm{~min}$ at room temperature a copper layer had formed. This layer had the typical view of massive copper. The thickness was about $0.3 \mu \mathrm{m}$. The adsorbed AuNP were used here as catalytic seeds for chemical plating. The cross-hatch test did not show any delamination of the copper film, and there was no delamination after peeling off an adhesive tape, pointing to a high adhesion, see Figure 5. The cross-hatch test had a value of zero. Similar experiments were carried out using a nickel bath with a rinsing time in the nickel solution of $10 \mathrm{~min}$, resulting in deposition of a nickel layer of $0.1 \mu \mathrm{m}$ with high adhesion. In contrast, no adsorption of AuNP and, consequently, no formation of a metal layer took place on a plain PEEK surface. Moreover, the covalently grafted polyamine layers can be used for attaching different organic layers, e.g., hydrogel layers, see Supplementary Materials.

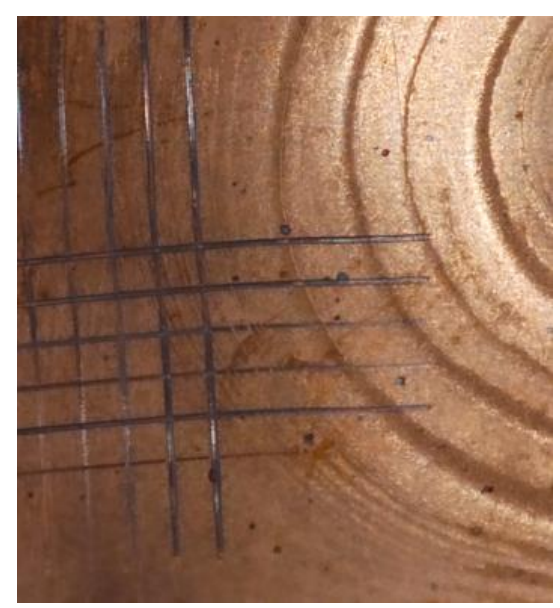

Figure 5. Photograph of a PEEK-copper composite made by chemical plating, after cross-hatch and peel test.

\section{Conclusions}

It was shown that polyamines bearing primary amino groups can be grafted to the surface of PEEK parts during molding. Grafting took place exploiting the melt temperature for initiating a chemical reaction, where the ketone groups of PEEK and the primary amino groups were connected under the formation of azomethine bonds. The chemical properties and behavior of these modified PEEK surfaces were dominated by the attached polyamines. The polyamine layer adsorbed gold seeds. The use of other seeds may also be possible, e.g., Pd or Ag. The seeds and the functional surface can then be used for chemical plating of PEEK with $\mathrm{Cu}$ or $\mathrm{Ni}$, e.g., for protective or decorative coatings or for electromagnetic shielding. Those metal-PEEK composites will support the application of PEEK in lightweight constructions. Moreover, plating only takes place at sites, where the modifier was applied to the mold prior to injection of the melt. Consequently, site-selective plating and the formation of metal structures on a surface becomes possible, as in the production of molded interconnected devices or circuit boards. The thermal stability of PEEK would enable the soldering of those circuit boards.

The high adhesion may be a result of the strong attraction of copper and nickel ions because the polyamines are strong chelating ligands of these metal ions. Probably, there are also strong interactions to metals, which supported high adhesion of the metal film [11]. These films are useful for the deposition of different metal layers by conventional galvanic plating processes. 
Supplementary Materials: The following are available online at http:/ /www.mdpi.com/2079-6412/8/10/333/s1, Figure S1: PEEK part modified with PAAm immersed in Eosin Y solution, Figure S2: EDX mapping of a PEEK surface, modified by PAAm during molding, Figure S3: Zeta potential as a function of $\mathrm{pH}$ for different samples, Figure S4: PEEK part modified with PAAm, immersed in AuNP solution, Figure S5: Photographs of different PEEK plates, spin-coated with a hydrogel, Table S1: Raw data of contact angle measurements.

Author Contributions: Conceptualization and supervision, J.N.; Sample preparation, characterization and plating, P.Z.; Electro kinetic investigations, S.S.; Microscopic and spectroscopic investigations, K.S.

Funding: This research received no external funding.

Acknowledgments: The authors wish to thank Anja Caspari for thorough measurements of the zeta potentials. Renè Weihrauch from University of Applied Science in Zittau is thanked for measurements of the metal layer thicknesses by RFA.

Conflicts of Interest: The authors declare no conflict of interest.

\section{References}

1. Laurens, P.; Sadras, B.; Decobert, F.; Arefi-Khonsari, F.; Amouroux, J. Enhancement of the adhesive bonding properties of PEEK by excimer laser treatment. Int. J. Adhes. Adhes. 1998, 18, 19-27. [CrossRef]

2. Ma, R.; Tang, T. Current strategies to improve the bioactivity of PEEK. Int. J. Mol. Sci. 2014, 15, 5426-5445. [CrossRef] [PubMed]

3. Kwon, G.; Kim, H.; Gupta, K.C.; Kang, I.-K. Enhanced tissue compatibility of polyetheretherketone disks by dopamine-mediated protein immobilization. Macromol. Res. 2018, 26, 128-138. [CrossRef]

4. Kim, K.H.; Im, S.H.; Park, B.J. Long-term stable hydrophilic surface modification of poly(ether ether ketone) via the multilayered chemical grafting method. J. Appl. Polym. Sci. 2018, 135, 46042. [CrossRef]

5. Rochford, E.T.J.; Poulsson, A.H.C.; Varela, J.S.; Lezuo, P.; Richards, R.G.; Moriarty, T.F. Bacterial adhesion to orthopaedic implant materials and a novel oxygen plasma modified PEEK surface. Colloid Surf. B Biointerfaces 2014, 113, 213-222. [CrossRef] [PubMed]

6. Al-Maliki, H.; Zsidai, L.; Samyn, P.; Szakal, Z.; Keresztes, R.; Kalacska, G. Effects of atmospheric plasma treatment on adhesion and tribology of aromatic thermoplastic polymers. Polym. Eng. Sci. 2018, 58, E93-E103. [CrossRef]

7. Salerno, S.; Piscioneri, A.; Laera, S.; Morelli, S.; Favia, P.; Bader, A.; Drioli, E.; De Bartolo, L. Improved functions of human hepatocytes on $\mathrm{NH}_{3}$ plasma-grafted PEEK-WC-PU membranes. Biomaterials 2009, 30, 4348-4356. [CrossRef] [PubMed]

8. Stefanikova, R.; Kretkova, T.; Kuzminova, A.; Hanus, J.; Vaidulych, M.; Kylian, O.; Biederman, H. Influence of atmospheric pressure dielectric barrier discharge on wettability and drying of poly(ether-ether-ketone) foils. Polym. Degrad. Stabil. 2018, 150, 114-121. [CrossRef]

9. Tsougeni, K.; Vourdas, N.; Tserepi, A.; Gogolides, E.; Cardinaud, C. Mechanisms of oxygen plasma nanotexturing of organic polymer surfaces: From stable super hydrophilic to super hydrophobic surfaces. Langmuir 2009, 25, 11748-11759. [CrossRef] [PubMed]

10. Schroder, K.; Meyer-Plath, A.; Keller, D.; Besch, W.; Babucke, G.; Ohl, A. Plasma-induced surface functionalization of polymeric biomaterials in ammonia plasma. Contrib. Plasma Phys. 2001, 41, 562-572. [CrossRef]

11. Briem, D.; Strametz, S.; Schroder, K.; Meenen, N.M.; Lehmann, W.; Linhart, W.; Ohl, A.; Rueger, J.M. Response of primary fibroblasts and osteoblasts to plasma treated polyetheretherketone (PEEK) surfaces. J. Mater. Sci. Mater. Med. 2005, 16, 671-677. [CrossRef] [PubMed]

12. Gomathi, N.; Sureshkumar, A.; Neogi, S. RF plasma-treated polymers for biomedical applications. Curr. Sci. 2008, 94, 1478-1486.

13. Tsougeni, K.; Papageorgiou, D.; Tserepi, A.; Gogolides, E. "Smart" polymeric microfluidics fabricated by plasma processing: Controlled wetting, capillary filling and hydrophobic valving. Lab Chip 2010, 10, 462-469. [CrossRef] [PubMed]

14. Ha, S.W.; Hauert, R.; Ernst, K.H.; Wintermantel, E. Surface analysis of chemically-etched and plasma-treated polyetheretherketone (PEEK) for biomedical applications. Surf. Coat. Technol. 1997, 96, 293-299. [CrossRef]

15. Iqbal, H.M.S.; Bhowmik, S.; Benedictus, R. Surface modification of high performance polymers by atmospheric pressure plasma and failure mechanism of adhesive bonded joints. Int. J. Adhes. Adhes. 2010, 30, 418-424. [CrossRef] 
16. Inagaki, N.; Tasaka, S.; Horiuchi, T.; Suyama, R. Surface modification of poly(aryl ether ether ketone) film by remote oxygen plasma. J. Appl. Polym. Sci. 1998, 68, 271-279. [CrossRef]

17. Awaja, F.; Cools, P.; Lohberger, B.; Nikiforov, A.Y.; Speranza, G.; Morent, R. Functionalized, biocompatible, and impermeable nanoscale coatings for PEEK. Mater. Sci. Eng. C Mater. Biol. Appl. 2017, 76, 865-870. [CrossRef] [PubMed]

18. Mathieson, I.; Bradley, R.H. Improved adhesion to polymers by UV/ozone surface oxidation. Int. J. Adhes. Adhes. 1996, 16, 29-31. [CrossRef]

19. Liu, S.; Zhu, Y.; Gao, H.; Ge, P.; Ren, K.; Gao, J.; Cao, Y.; Han, D.; Zhang, J. One-step fabrication of functionalized poly(etheretherketone) surfaces with enhanced biocompatibility and osteogenic activity. Mater. Sci. Eng. C Mater. Biol. Appl. 2018, 88, 70-78. [CrossRef] [PubMed]

20. Ishihara, K.; Fukazawa, K.; Inoue, Y.; Koyama, J.; Mori, Y.; Kinoshita, T.; Hiranuma, K.; Yasuda, N. Reliable surface modification of dental plastic substrates to reduce biofouling with a photoreactive phospholipid polymer. J. Appl. Polym. Sci. 2018, 135, 46512. [CrossRef]

21. Rymuszka, D.; Terpiłowski, K.; Borowski, P.; Holysz, L. Time-dependent changes of surface properties of polyether ether ketone caused by air plasma treatment: Air plasma treatment of polyether ether ketone. Polym. Int. 2016, 65, 827-834. [CrossRef]

22. Morent, R.; De Geyter, N.; Leys, C.; Gengembre, L.; Payen, E. Study of the ageing behaviour of polymer films treated with a dielectric barrier discharge in air, helium and argon at medium pressure. Surf. Coat. Technol. 2007, 201, 7847-7854. [CrossRef]

23. Noiset, O.; Schneider, Y.J.; Marchand-Brynaert, J. Fibronectin adsorption or and covalent grafting on chemically modified PEEK film surfaces. J. Biomater. Sci. Polym. Ed. 1999, 10, 657-677. [CrossRef] [PubMed]

24. Riveiro, A.; Soto, R.; Comesana, R.; Boutinguiza, M.; Del Val, J.; Quintero, F.; Lusquinos, F.; Pou, J. Laser surface modification of PEEK. Appl. Surf. Sci. 2012, 258, 9437-9442. [CrossRef]

25. Rotel, M.; Zahavi, J.; Tamir, S.; Buchman, A.; Dodiuk, H. Pre-bonding technology based on excimer laser surface treatment. Appl. Surf. Sci. 2000, 154, 610-616. [CrossRef]

26. Lee, K.S.; Shin, M.S.; Lee, J.Y.; Ryu, J.J.; Shin, S.W. Shear bond strength of composite resin to high performance polymer PEKK according to surface treatments and bonding materials. J. Adv. Prosthodont. 2017, 9, 350-357. [CrossRef] [PubMed]

27. Lee, J.A.; McCarthy, T.J. Polymer surface modification: Topography effects leading to extreme wettability behavior. Macromolecule 2007, 40, 3965-3969. [CrossRef]

28. Nagel, J.; Scheidler, D.; Hupfer, B.; Bräuer, M.; Pleul, D.; Vogel, C.; Lehmann, D.; Amesöder, S. Investigations on the formation of composites by injection molding of PA6 and different grafted polypropylenes and their blends. J. Appl. Polym. Sci. 2006, 100, 2992-2999. [CrossRef]

29. Nagel, J.; Bräuer, M.; Hupfer, B.; Grundke, K.; Schwarz, S.; Lehmann, D. Investigations on the reactive surface modification of polycarbonate by surface-reactive injection molding. J. Appl. Polym. Sci. 2004, 93, 1186-1191. [CrossRef]

30. Brunotte, R.; Mennig, G.; Nagel, J. In-situ surface modification of polycarbonate during injection moulding. J. Plast. Technol. 2006, 2, 1-7.

31. Nagel, J.; Brunotte, R.; Hupfer, B.; Grundke, K.; Lehmann, D.; Mennig, G. Investigations into the chemical modification of polyolefin surfaces by radical reactions during molding. Macromol. React. Eng. 2007, 1, 480-487. [CrossRef]

32. Brunotte, R.; Nagel, J.; Mennig, G.; Heinrich, G.; Gehde, M. Polyolefin surface modification during injection molding using radical reactions in liquid phase. Macromol. React. Eng. 2014, 8, 412-417. [CrossRef]

33. Nagel, J.; Zimmermann, P.; Schubert, O.; Simon, F.; Schlenstedt, K. Coupling of carboxylic groups onto the surface of polystyrene parts during fused filament fabrication. Appl. Surf. Sci. 2017, 422, 28-31. [CrossRef]

34. Kroschwald, F.; Nagel, J.; Janke, A.; Simon, F.; Zimmerer, C.; Heinrich, G.; Voit, B. Gold nanoparticle layers from multi-step adsorption immobilised on a polymer surface during injection molding. J. Appl. Polym. Sci. 2016, 133, 43608. [CrossRef]

35. Ruiz-Cabello, F.M.; Rodríguez-Valverde, M.A.; Cabrerizo-Vilchez, M.A. Contact angle hysteresis on polymer surfaces: An experimental study. J. Adhes. Sci. Technol. 2011, 25, 2039-2049. [CrossRef]

36. Manolakis, I.; Cross, P.; Colquhoun, H.M. Direct iminization of PEEK. Macromolecules 2011, 44, 7864-7867. [CrossRef] 
37. Yurchenko, M.E.; Huang, J.; Robisson, A.; McKinley, G.H.; Hammond, P.T. Synthesis, mechanical properties and chemical/solvent resistance of crosslinked poly(aryl-ether-ether-ketones) at high temperatures. Polymer 2010, 51, 1914-1920. [CrossRef]

38. Wright, M.D. Glyoxalated N-Vinylamine. U.S. Patent 8262859 B2, 11 September 2012.

39. Thompson, S.A.; Farris, R.J. A novel method for crosslinking polyetheretherketone. J. Appl. Polym. Sci. 1988, 36, 1113-1120. [CrossRef]

40. Becker, M.; Lorenz, S.; Strand, D.; Vahl, C.F.; Gabriel, M. Covalent grafting of the RGD-peptide onto polyetheretherketone surfaces via schiff base formation. Sci. World J. 2013, 2013, 616535. [CrossRef] [PubMed]

41. Franchina, N.L.; McCarthy, T.J. Surface modifications of poly(ether ether ketone). Macromolecules 1991, 24, 3045-3049. [CrossRef]

42. Nagel, J.; Heinrich, G. Temperature transitions on the surface of a thermoplastic melt during injection moulding and its use for chemical reactions. Int. J. Heat Mass Transf. 2012, 55, 6890-6896. [CrossRef]

43. Helfand, E.; Tagami, Y. Theory of the interface between immiscible polymers. J. Polym. Sci. Part B 1971, 9, 741-746. [CrossRef]

(C) 2018 by the authors. Licensee MDPI, Basel, Switzerland. This article is an open access article distributed under the terms and conditions of the Creative Commons Attribution (CC BY) license (http://creativecommons.org/licenses/by/4.0/). 